\title{
Autoimmune Hepatitis: Clinical Review with Insights into the Purinergic Mechanism of Disease
}

\author{
Nikhil Kapila ${ }^{\ddagger}$, Jennifer T. Higa ${ }^{2}$, Maria Serena Longhi ${ }^{2,3}$ and Simon C. Robson ${ }^{2}$ \\ ${ }^{1}$ Department of Medicine, University of Connecticut, Farmington, CT, USA; ${ }^{2}$ Gastroenterology Division and Department of \\ Medicine, Beth Israel Deaconess Medical Center and Harvard Medical School, Boston, MA, USA; ${ }^{3}$ Institute of Liver Studies, \\ King's College London School of Medicine at King's College Hospital, Denmark Hill, London, UK
}

\begin{abstract}
Autoimmune hepatitis (AIH) is an important disorder that predominantly results in inflammatory liver disease in genetically predisposed women. The clinicopathological picture is characterized by symptoms associated with both systemic inflammation and hepatic dysfunction, and with increased serum aminotransferases, elevated IgG, autoantibodies, and interface hepatitis on liver biopsy. AIH usually results in liver injury as a consequence of chronic hepatitis and cirrhosis. However, rarely, patients may present with fulminant liver failure. Early diagnosis is important in all instances because the disease can be highly responsive to immunosuppressive therapeutic options. Left untreated, the disease is associated with high morbidity and mortality. Here we provide an overview of the current state of knowledge on $\mathrm{AIH}$ and summarize the treatment options for this serious condition in adults. We also discuss the pathogenesis of the disease as a possible consequence of autoimmunity and the breakdown of hepatic tolerance. We focus on regulatory $T$ cell impairments as a consequence of changes in CD39 ectonucleotidase expression and altered purinergic signaling. Further understanding of hepatic tolerance may aid in the development of specific and well-tolerated therapies for $\mathrm{AIH}$.

(C) 2013 The Second Affiliated Hospital of Chongqing Medical University. Published by XIA \& HE Publishing Ltd. All rights reserved.
\end{abstract}

\section{Introduction}

In 1950, Jan Waldenstrom described the first case of autoimmune hepatitis (AIH) in a woman with hepatic

Keywords: Autoimmune hepatitis; Pathogenesis; Immunology; Purinergic; CD39; Therapeutic overview.

Abbreviations: $\mathrm{AIH}$, autoimmune hepatitis; ANA, anti-nuclear antibody; ANCA, anti-neutrophil cytoplasmic antibodies; anti-LC1, antibodies to liver cytosol type 1 ; anti-LKM1, antibodies to liver-kidney microsome type 1 ; AZA, azathioprine; FTCD, formiminotransferase cyclodeaminase; HLA, human leukocyte antigen; LC1, liver cytosol antibody; LP, liver pancreas; MHC, major Histocompatibility Complex; MMF, mycophenolate mofetil; NKT, natural killer T; OLT, orthotopic liver transplantation; SepSecS, O-phosphoseryl-tRNA: selenocysteinyl-tRNA synthase; SLA, soluble liver antigen; SMA, smooth muscle antibody; TMPT, thiopurine methyltransferase; Treg, regulatory $T$ cell.

Received: 30 August 2013; Revised: 4 October 2013; Accepted: 15 October 2013 DOI of original article: 10.14218/JCTH.2013.00015.

Correspondence to: Simon C. Robson, Division of Gastroenterology, CLS 612, Beth Israel Deaconess Medical Centre/Harvard Medical School, Boston MA 02215, USA Tel: +1-617-735-2921, Fax: +1-617-735-2930, Email: srobson@bidmc.harvard.edu *These authors contributed equally to this work. dysfunction and hypergammaglobulinemia. ${ }^{1,2}$ Since then, AIH has become a well-established clinical entity, albeit uncommon, with an estimated annual incidence of 1.9 per 100,000 , and a prevalence of $10-20 / 100,000 .^{3}$ Early diagnosis is important, as AIH usually responds to immunosuppressive treatment. However, if left untreated, AIH can progress to liver failure, cirrhosis, and death.

In this updated review, we explore the pathogenesis of $\mathrm{AIH}$, consider the immunological basis for the pathogenesis of liver-directed immune injury, and present new concepts in the understanding of immune tolerance that seem to be perturbed in $\mathrm{AIH}$. We also comment on various developments in innovative treatment modalities.

\section{Clinical presentation}

AIH may present with a variety of clinical manifestations, ranging from asymptomatic disease to fulminant liver failure. Although up to $25 \%$ of patients may be asymptomatic at diagnosis, ${ }^{4}$ the condition most commonly presents in an insidious manner with non-specific complaints in young or middle-aged women. ${ }^{5}$ Approximately $30 \%$ of patients may have evidence of advanced liver disease and cirrhosis at the time of diagnosis. ${ }^{6}$ Extrahepatic manifestations of AIH may include inflammatory bowel disease, thyroiditis, type- 1 diabetes mellitus, and celiac disease. 7,8

There are no pathognomonic features of AIH. Therefore, the diagnosis depends on a set of clinicopathological, histological, biochemical, and immunological criteria. Interface hepatitis is the histological hallmark of AIH (see Fig. 1) and is present in $84-98 \%$ of cases. ${ }^{8}$ Biopsy findings of cirrhosis and/or bridging necrosis carry a poorer prognosis than those lacking these features. ${ }^{5,8,9}$

Multiple biochemical derangements can be found in AIH. Most commonly, elevated aminotransferases with or without elevated bilirubin and alkaline phosphatase are frequently seen. Serum immunoglobulins, notably IgG, are elevated in approximately $85 \%$ of cases. ${ }^{8}$

Several scoring systems are available to aid in making an objective diagnosis and prognostication of AIH. In 1992, the International Autoimmune Hepatitis Group (IAIHG) published the first scoring system for $\mathrm{AIH}$, with a revision released in 1999. ${ }^{10}$ A simplified scoring system was published in 2008, which was subsequently vetted and shown to have high specificity. ${ }^{11,12}$ 

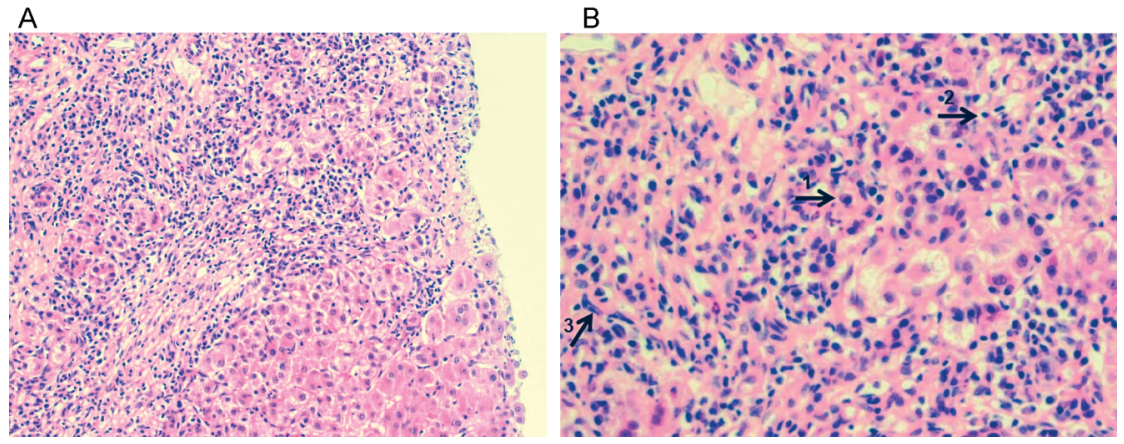

Fig. 1. Histological picture of AIH. (A) Portal and peri-portal inflammatory infiltrate, characteristic of autoimmune hepatitis, consists of (B) plasma cells, lymphocytes and monocytes/macrophages, as phenotypically indicated by arrows labeled 1, 2, and 3, respectively. There is evidence of interface hepatitis and piecemeal necrosis of hepatocytes. Hematoxylin and eosin staining, magnification $\times 200$ (A) and x400 (B). (Credit: Dr Alberto Quaglia).

\section{Serologic markers of disease}

Autoantibodies are important in making the diagnosis of $\mathrm{AIH}$, and aside from confirming the diagnosis, serologic markers may assist in subtyping the disease and determining the prognosis. $^{11}$

\section{Diagnostic markers}

Conventional markers for AIH include anti-smooth muscle antibody (SMA) and anti-nuclear antibody (ANA), both of which characterize the classic type 1 AIH. SMA positivity appears to be more specific for AIH than ANA, which is associated with multiple sero-reactants to centromere, histones, double-stranded DNA, chromatin, and ribonucleoprotein complex components, and thus has yet to yield a specific antigenic target. ${ }^{13-17}$ The specific antigen of SMA is also not clear, although multiple studies suggest that these autoantibodies react with actin components. ${ }^{18,19}$

It has also been reported that anti-nuclear and other autoantibodies are frequently noted in patients with nonalcoholic steatohepatitis. These observations may represent either nonspecific antibody responses associated with liver injury, or an autoimmune diathesis that may be linked pathogenetically to chronic inflammation, as in steatohepatitis. ${ }^{20-22}$

Antibodies to liver-kidney microsome type 1 (anti-LKM1) and liver cytosol type 1 (anti-LC1) characterize type 2 AIH. This subtype was described in the 1980s after the discovery of antibodies to liver-kidney microsomes. ${ }^{23-25}$ Typically, patients are young women with more severe disease. The antigenic target of anti-LKM1 was identified as the cytochrome P450 liver enzyme CYP2D6. ${ }^{26,27}$

\section{Adjunctive markers}

Anti-soluble liver antigen (SLA) and liver pancreas (LP) reactivity are specific to and positive in $58 \%$ of adult patients with type 1 AIH. ${ }^{1,28,29}$ The antigens for SLA/LP include ribonucleoprotein complex and O-phosphoseryltRNA:selenocysteinyl-tRNA synthase (SepSecS). ${ }^{30}$ Anti-SLA is often associated with severe disease. ${ }^{31}$

Liver cytosol antibody (LC1) was described in the $1980 \mathrm{~s},{ }^{32}$ and is useful as an adjunct in the diagnosis of AIH type 2. The LC1 antigen is the liver-expressed enzyme formiminotransferase cyclodeaminase (FTCD), and appears to be associated with early onset of disease, concurrent autoimmunity, and rapid progression to cirrhosis. ${ }^{31}$ LC- 1 titers fluctuate with disease activity. ${ }^{33,34}$ Rarely, anti-neutrophil cytoplasmic antibodies (ANCA) are associated with primary sclerosing cholangitis (PSC) overlap syndrome, and high rates of cirrhosis. ${ }^{35-38}$

\section{Pathogenesis}

The following pathogenetic model has been proposed: in a genetically predisposed host, defined environmental agent(s) catalyze(s) and trigger a series of T cell-mediated immune events directed at hepatic cellular antigens, resulting in unfettered inflammation, which ultimately culminates in fibrotic transformation of the liver, aberrant regeneration, and cirrhosis. ${ }^{5,29,39}$

\section{Genetic predisposition}

The genetic predisposition to AIH has been attributed, at least in part, to specific allelic variations in the major histocompatibility complex (MHC), located on chromosome 6 in the human leukocyte antigen (HLA) region. ${ }^{31,40}$ Among Caucasian populations, associations between AIH type 1 and DRB1 alleles (DRB1*0301, DRB1*0401), as well as between AIH type 2 and allele DRB1*0701 have been described. Patients with DRB1*0301 tend to be younger, more likely to require liver transplant, and experience higher rates of acute liver failure and steroid treatment failure. ${ }^{34,41}$ HLA allelic associations vary globally. ${ }^{37}$

Genetic risk factors outside of the MHC include polymorphisms of the gene for cytotoxic T lymphocyte antigen 4 (CTLA-4) in white North American and European populations. The CTLA-4 molecule interaction with antigen-presenting cells has been shown to mitigate $T$ cell activation.

Further, a polymorphism of the gene encoding for tumor necrosis factor alpha (TNF 2 ), which is involved in the upregulation of type 1 cytokines, is associated with more severe AIH in young white patients whose disease may be steroidresistant. ${ }^{42,43}$

\section{Molecular mimicry}

Discovery and understanding of the target antigens for the autoantibodies in AIH may be important for developing specific treatments and understanding the mechanisms of 
Kapila N. et al: Autoimmune hepatitis management pathogenesis purinergic review

the disease. Molecular mimicry describes natural genetic homologies between autoantigens and common viral genomes (hepatitis $\mathrm{C}$ virus, herpes simplex virus 1, cytomegalovirus (CMV)) that spawn autoantibodies. ${ }^{33,44}$ This genetic interplay is feasible because of incomplete specificity at CD4+ T-cell antigen receptors. ${ }^{33}$

\section{Cellular immunoregulation}

Immune system homeostasis is accomplished through regulation of effector CD8+ and CD4+ T cells by CD4+CD25+CD39+FOXP3+ regulatory $T$ cells (Tregs). ${ }^{45,46} \mathrm{~A}$ major contributor to AIH pathogenesis is the failure of immunoregulation as a result of diminished function and sheer number of Tregs, with consequent massive recruitment of inflammatory effector cells, which inflict hepatic injury. ${ }^{47,48}$

Tregs express unique markers including the interleukin$2 \mathrm{R} \alpha(\mathrm{IL}-2 \mathrm{R} \alpha)$ chain (CD25), the glucocorticoid induced tumor necrosis factor receptor (GITR), CD62L, CTLA-4, and forkhead/winged helix transcription factor (FOXP3) as well as CD39, an ectonucleotidase responsible for extracellular nucleotide phosphohydrolysis, culminating in the production of immunosuppressive adenosine and regulated purinergic signaling. $39,47,49-53$

There is fairly recent evidence indicating that adenosine modulates effector cells by up-regulating inhibitory molecules (i.e. CTLA-4 and programmed-cell-death-protein-1 (PD1)), by decreasing IL-2 production and proliferation, and by inhibiting differentiation of effector cells into $T$ helper 1 (Th1) and Th17 cell lineages. ${ }^{54}$ The immunomodulating effects of adenosine are mediated by the binding of the nucleoside to $\mathrm{A} 2 \mathrm{~A}$ adenosine receptors on effector $\mathrm{T}$ cells. There are multiple putative Treg defects in common diseases that might contribute to a model of impaired immunoregulation in $\mathrm{AIH}$ and other immunological illnesses. ${ }^{55}$ In very recent work, we and our colleagues showed that the CD39expressing Tregs are decreased and lack the functional capacity to efficiently limit production of IL17, a proinflammatory cytokine elevated in the serum of patients with AIH. ${ }^{56,57}$ The mechanism by which CD39+ Tregs limit IL17 production is unclear, although it has been previously suggested that CD39 can decrease IL17 levels by removal of ATP. ${ }^{58}$

Tregs in AIH exhibit slow rates of phosphohydrolysis of pro-inflammatory nucleotides compared to matched control cells. It has been proposed that defective immunoregulation in AIH is associated not only with decreased Treg number and functions, but also increased conversion of Tregs into effectors as a result of predominance of pro-inflammatory cytokines in the environment. The reasons for CD39 downregulation or loss from Tregs in AIH are unknown, although reduced levels of transforming growth factor- $\beta$ (TGF- $\beta$ ), an inhibitory cytokine that promotes CD39 upregulation on human leukocytes, ${ }^{59}$ may account for this observation. Such a model of Treg CD39 dysregulation leading to autoimmune attack is depicted in Fig. 2. Such pathways may also be implicated in other autoimmune disorders of the gastrointestinal tract, such as inflammatory bowel disease. ${ }^{60}$

Treatment-induced remission of $\mathrm{AIH}$ is associated with restoration of Treg function. ${ }^{61}$ Some groups have looked at expansion of Treg populations or diminishing effects of cytokine IL-17 as possible therapeutic interventions. ${ }^{56,57,62}$

Natural killer T (NKT) cells may also be involved in the pathogenesis of AIH. NKT cells are found in the vascular sinusoids, potentially providing an immunological bridge between innate and adaptive immune responses in immune liver reactions.

The purinergic receptor $\mathrm{P} 2 \mathrm{X} 7$ recognizes extracellular ATP, and is crucial in regulating the function of NKT cells. ${ }^{63}$ It has been proposed that the $\mathrm{P} 2 \mathrm{X} 7$ receptor constitutes a sensor that can modulate NKT cell functions, which would also be affected by the ectonucleotidase CD39 expressed by these cells. ${ }^{64}$ Curiously, genetic deletion in CD39, which limits Treg functions exacerbating adaptive immune responses in transplant rejection models, ${ }^{65}$ also results in increased rates of stimulated NKT cell apoptosis in mouse models of AIH. ${ }^{66}$ Hence, concanavalin-A hepatitis induction in Cd39 null mice results in enhanced levels of NKT cell loss and paradoxical protection from liver injury. This unexpected experimental finding illustrates the complexity of purinergic signaling in influencing diverse immune cell types (Treg vs. NKT cells) and in dictating opposing outcomes in the immune liver injury.

\section{Treatment}

\section{Prednisone/azathioprine}

The standard treatment for AIH comprises corticosteroid, and prednisone at an initial dose of 40-60 mg daily followed by combinations of prednisone in tapering doses to the lowest levels required to maintain remission with the anti-metabolite immune suppressant azathioprine (AZA) added to the therapeutic regimen. IN the USA, the daily dose of AZA is generally $50 \mathrm{mg}$, whereas in Europe, a higher dose of 1$2 \mathrm{mg} / \mathrm{kg}$ is usually preferred. ${ }^{65}$ Several clinical trials in the 1970 's demonstrated the safety and efficacy of this regimen, with remission rates of $65-80 \% .{ }^{5,67}$ However, many of the American Association for the Study of Liver Diseases (AASLD) and British Society of Gastroenterology consensus guidelines for the standardized management of AIH are based on suboptimal studies, and there remain clear uncertainties as to the management of refractory or resistant cases. ${ }^{68-71}$

Prolonged therapy may potentially result in a variety of adverse events that may lead to non-compliance and early cessation of therapy in a minority of patients.

Approximately $13 \%$ of patients discontinue conventional therapy because of intolerable prednisone-related side effects, with nearly half of these patients discontinuing therapy because of intolerable cosmetic issues. Similarly, long-term AZA use is associated with a constellation of potential side effects. Approximately $5 \%$ of patients treated with AZA cannot tolerate the side effects, and require early discontinuation of therapy. The most notable side effect is pancytopenia. Risk factors for this complication include malnutrition, cirrhosis, and absent $(1: 300)$ or low-level expression (10\%) of thiopurine methyltransferase (TMPT) ${ }^{72,73}$ It is increasingly accepted that TPMT testing should be performed prior to starting thiopurine drugs.

Other potential side effects of AZA include pancreatitis, cholestatic liver injury, vascular sinusoidal injury with nodular regenerative hyperplasia, and development of opportunistic infection. ${ }^{74}$

In 2010, the updated guidelines for the management of AIH redefined remission as sustained normalization of liver enzymes, ${ }^{9,69,75-77}$ including a goal of normalized IgG/gammaglobulins. ${ }^{9}$ Histological remission lags behind biochemical remission by 3-8 months. Although remission is achieved in the majority of patients with conventional management, $50 \%$ 
Kapila N. et al: Autoimmune hepatitis management pathogenesis purinergic review

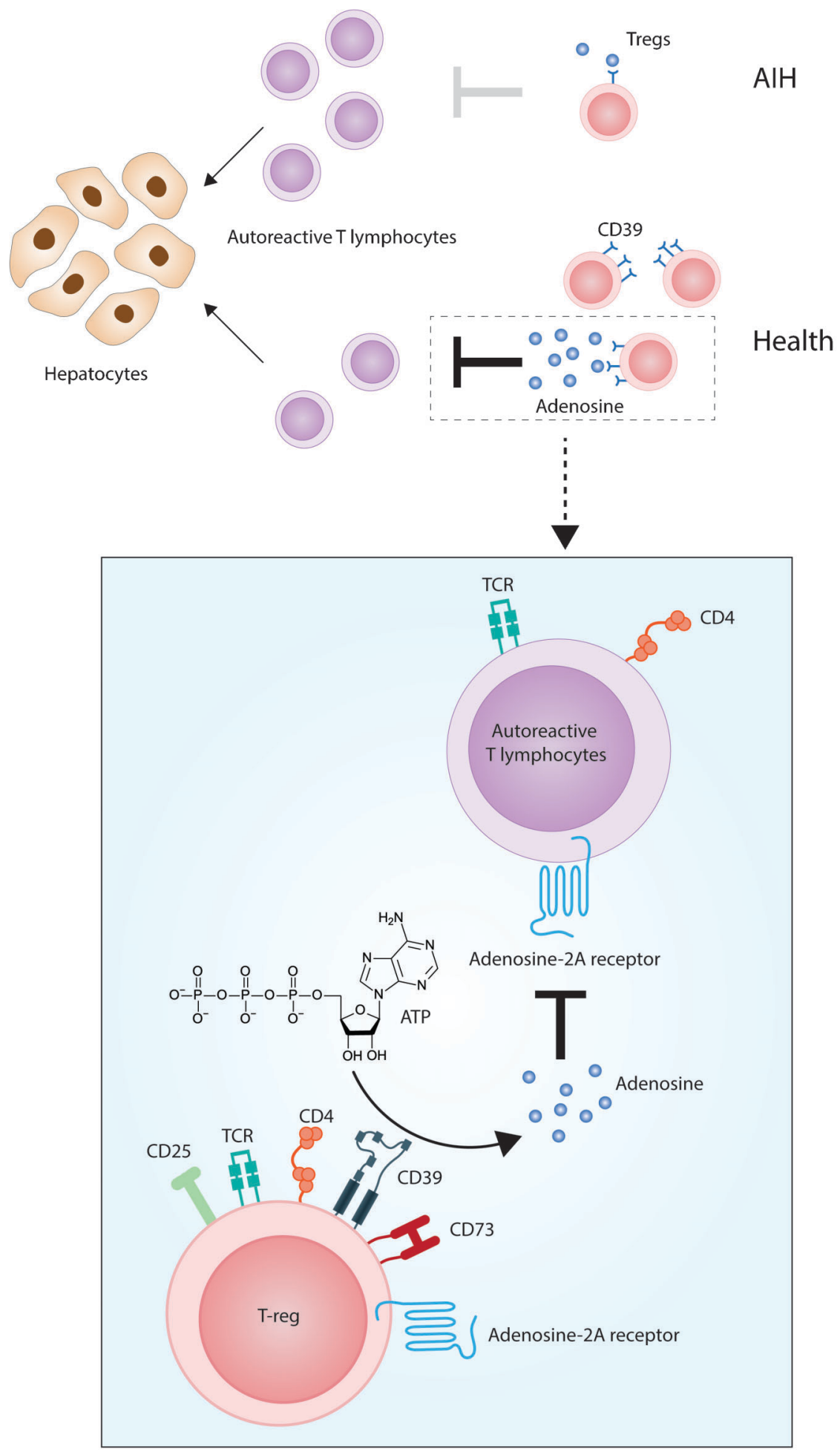

Fig. 2. Pathogenesis of liver attack in AIH: the role of CD39. In health, immunotolerance to liver autoantigens is maintained by effective control of CD4+CD25+FOXP3+Tregs over CD4+ and CD8+ autoreactive T lymphocytes. The machinery enabling Tregs to modulate effector immune responses relies on the expression of CD39, an ectonucleotidase ultimately leading to the generation of immunomodulatory adenosine. In AIH, Tregs are numerically defective and express low levels of CD39. This results in poor generation of adenosine and ineffective control over autoreactive lymphocytes, with consequent perpetuation of hepatocyte damage. Details of Treg adenosinergic suppression are depicted in the box. Adenosine is generated from ATP through the action of CD39 and CD73 ectonucleotidases in tandem, expressed by Tregs. Adenosine mediates immunomodulation by binding to A2A adenosine receptors on autoreactive $\mathrm{T}$ lymphocytes. 
Kapila N. et al: Autoimmune hepatitis management pathogenesis purinergic review

of patients relapse within 6 months of cessation of immunosuppressive therapy, and nearly $70 \%$ within 3 years. ${ }^{71}$ Achieving histological remission reduces the frequency of relapse to approximately $28 \%$, while evidence of even mild portal hepatitis or inflammation increases the frequency to greater than $50 \% .^{78}$

\section{Budesonide}

Budesonide is a synthetic, orally administered corticosteroid with a rate of hepatic first-pass metabolism of $80-90 \%{ }^{79}$ The drug is metabolized in the liver to by-products that have negligible glucocorticoid activity, but a marked affinity for glucocorticoid receptors. In 1994, Danielsson and Prytz studied the use of budesonide with or without $A Z A^{80}$ (see Table 1). Since then multiple small studies ${ }^{81-83}$ have preceded the first prospective, clinical trial studying the use of budesonide in AIH by Manns et al. in 2010.84

There is increasing evidence supporting budesonide as an alternative to prednisone. As demonstrated in published accounts, budesonide appears to be similar in efficacy to but more tolerable than prednisone. Although the Mayo Clinic series did not find any benefit with this alternative use of budesonide, other studies have demonstrated its efficacy and favorable side effect profile. ${ }^{85}$

Because the drug is metabolized almost exclusively in the liver, it may be intolerable to patients with cirrhosis. Additionally, patients exposed to prednisone may experience significant corticoid-related side effects when transitioning to budesonide. ${ }^{85}$ Further follow-up regarding sustained remission with budesonide is required.

\section{Mycophenolate mofetil}

Mycophenolate mofetil (MMF) is the prodrug of mycophenolic acid, which is a potent, irreversible inhibitor of inosine monophosphate dehydrogenase, and has prominent cytostatic effects on lymphocytes. Richardson and colleagues published the first case series investigating usage of MMF in patients resistant to or intolerant of AZA. ${ }^{86}$ Multiple subsequent case series and retrospective reviews noted achievement of biochemical remission in the majority of refractory cases of $\mathrm{AIH}$, with a significant steroid-sparing effect. ${ }^{87-91}$ However, Czaja and Carpenter studied the use of MMF in eight patients, and found that none of the patients who previously failed conventional therapy responded to MMF as salvage therapy. ${ }^{92}$

In 2010, another group studied the role of MMF in treatment-naïve patients. At the end of the study there were no non-responders, while $59.3 \%$ of patients achieved a complete response, and $28.8 \%$ of patients had a complete response initially, followed by a relapse. ${ }^{93}$

MMF appears to be an effective agent in treatment-naïve disease. However, there is no clear consensus on the use of MMF as a second line agent in those patients who fail conventional management. It appears that MMF has a role to play in patients who were previously intolerant to conventional therapy. The role of MMF as a definitive second line

Table 1. Review of major literature on the use of budesonide in AIH

Study End Points Results

\begin{tabular}{|c|c|c|c|}
\hline Author & Year & No. of Patients & Budesonide Dose \\
\hline Danielsson & 1994 & 13 & $6-8 \mathrm{mg}$ daily \\
\hline Zandieh & 2008 & 9 & $\begin{array}{l}3 \mathrm{mg} \text { every other } \\
\text { day to } 9 \mathrm{mg} \text { daily }\end{array}$ \\
\hline Wiegand & 2005 & 12 & $\begin{array}{l}\text { Day 1: } 6 \text { mg daily } \\
\text { Day 2: } 9 \text { mg daily } \\
\text { Upon remission: } \\
6 \text { mg daily }\end{array}$ \\
\hline
\end{tabular}

Decrease in ALT, AST, IgG

Complete response: Normal ALT, AST

Complete remission:

AST and ALT drop $\leqslant$ two times the

upper limit of normal

Partial response:

ALT or AST $\leqslant$ two times the

upper limit of normal or

AST/ALT improvement

$>80 \%$ from baseline

\begin{tabular}{|c|c|c|c|}
\hline Csepregi & 2006 & 11 & 9 mg daily \\
\hline Manns & 2010 & $\begin{array}{l}203 \text { (100 } \\
\text { received } \\
\text { Budesonide and } \\
103 \text { received } \\
\text { prednisone) }\end{array}$ & $\begin{array}{l}6 \mathrm{mg} \text { daily or } \\
9 \mathrm{mg} \text { daily }\end{array}$ \\
\hline Czaja & 2000 & 10 & 9 mg daily \\
\hline
\end{tabular}

Remission:

Absence of symptoms

Normal ALT, ALP, IgG

\section{Complete response:}

Normal ALT

Normal AST

Absence of steroid-related

side effects

Remission:

Asymptomatic

Normal or near normal AST

Normal bilirubin

Normal $\gamma$-globulin

Failure:

Clinical/biochemical

deterioration

Complete response: $100 \%$

Complete response: $78 \%$

No response: $22 \%$

Complete response: $58 \%$

Partial response: $25 \%$

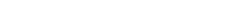

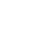

2000 Czaja 10 mg daily


Kapila N. et al: Autoimmune hepatitis management pathogenesis purinergic review

salvage agent requires further studies in the form of prospective controlled trials. The most common adverse reactions with MMF are gastrointestinal side effects, and significant thrombocytopenia, leukopenia, and rarely CMV infection. Considering that the treatment duration is often measured in years, the adverse effects associated with prolonged use of MMF in this population are yet to be determined. Additionally, judicious use of MMF must be employed given its greater cost compared to conventional treatment. 89

\section{Cyclosporin}

Cyclosporin is a calcineurin inhibitor that acts by binding to cyclophilin, thus creating a complex. ${ }^{94}$ Mistilis and colleagues first reported the use of cyclosporin in the management of AIH in $1985 .{ }^{95}$ Since then, several isolated case reports and case series have described the successful use of cyclosporin in adults intolerant or non-responsive to conventional management. ${ }^{96-100}$ Malekzadeh and colleagues in 2001 published the largest case series reporting the use of cyclosporin as an alternative to steroid-based treatment in $\mathrm{AIH} .{ }^{101}$ Although cyclosporin appears to have a promising role in the treatment of $\mathrm{AIH}$, the potential long-term adverse effects and nephrotoxicity of the drug have yet to be studied in this particular patient population.

\section{Tacrolimus}

Tacrolimus is a macrolide with a similar mechanism of action to cyclosporin but with greater immunosuppressive potency. Tacrolimus binds to the FK506 binding protein, thus inhibiting phosphatase activity, which is required for cytokine gene transcription and T-cell activation. The net result of tacrolimus activity is inhibition of both T and B cells. ${ }^{102}$

Treatment of $\mathrm{AIH}$ with tacrolimus was first proposed in $1995 .^{103}$ In an open label study, 15 of 21 patients demonstrated biochemical improvement. Multiple follow-up singlecenter studies on patients who were either steroid-refractory or steroid-intolerant demonstrated similar results. ${ }^{104,105} \mathrm{~A}$ review of the literature suggests that tacrolimus has a role to play in the management of patients intolerant and/or refractory to conventional therapy, and may be effective as a second line therapy in AIH. Adverse effects include nephrotoxicity, hypertension, bone marrow toxicity, diabetes, neurotoxicity, and opportunistic infections. ${ }^{106,107}$

\section{Alternative therapies}

Several isolated case reports have investigated other agents as potential alternatives to conventional management, including ursodeoxycholic acid, infliximab, etanercept, methotrexate, rapamycin and rituximab; however, rigorous supportive data is lacking.

\section{Transplantation}

Orthotopic liver transplantation (OLT) is reserved for those patients who have failed medical therapy or who present with acute fulminant hepatitis that is too advanced for medical management.

$\mathrm{AIH}$ is the indication for OLT in approximately $4-6 \%$ of adult transplants occurring in the USA and Europe. ${ }^{108}$ Outcomes are excellent in patients who undergo OLT for treatment of $\mathrm{AIH}$, with 5-year and 10 -year survival rates close to $75 \%$. Recent studies indicate that the rate of recurrence of $\mathrm{AIH}$ post-OLT is approximately $23 \% .{ }^{109}$ In these patients, modification of the immunosuppressive regimen and close follow-up is mandatory. ${ }^{9}$

\section{Conclusions}

AIH remains clinically challenging despite decades of awareness of this complex disease. Although standard therapy with prednisone and AZA frequently results in an excellent treatment response, the need for novel and steroid-sparing treatments remains. The goal is to optimize care for the wide spectrum of patients afflicted with this condition. Further exploration of the underlying immunologic processes in $\mathrm{AIH}$, particularly those which, at least in part, involve purinergic signaling, should be undertaken. This will lead to a deeper understanding of how the usual mechanisms of hepatic tolerance are rendered incompetent in this dangerous and yet fascinating liver disease.

\section{Conflict of interest}

None

\section{Author contributions}

Reviewing literature, conceiving concepts and developing the review (NY, JTH, MSL, SCR)

\section{Acknowledgments}

We thank Dr Alberto Quaglia for kindly providing the histological image used in this publication.

\section{References}

[1] Heneghan MA, Yeoman AD, Verma S, Smith AD, Longhi MS. Autoimmune hepatitis. Lancet 2013.

[2] WJ L. Blutproteine und Nahrungseiweib. Dtsch Z Verdau Stoffwechselkr 1950;15:113-119.el

[3] Boberg KM, Aadland E, Jahnsen J, Raknerud N, Stiris M, Bell H. Incidence and prevalence of primary biliary cirrhosis, primary sclerosing cholangitis, and autoimmune hepatitis in a Norwegian population. Scand J Gastroenterol 1998;33:99-103.

[4] Feld JJ, Dinh H, Arenovich T, Marcus VA, Wanless IR, Heathcote EJ. Autoimmune hepatitis: effect of symptoms and cirrhosis on natural history and outcome. Hepatology 2005;42:53-62.

[5] Krawitt EL. Autoimmune hepatitis. N Engl J Med 2006;354:54-66.

[6] Werner M, Prytz $H$, Ohlsson B, et al. Epidemiology and the initial presentation of autoimmune hepatitis in Sweden: a nationwide study. Scand J Gastroenterol 2008;43:1232-1240.

[7] Kaukinen K, Halme L, Collin P, et al. Celiac disease in patients with severe liver disease: gluten-free diet may reverse hepatic failure. Gastroenterology 2002;122:881-888.

[8] Gleeson D, Heneghan MA. British Society of Gastroenterology (BSG) guidelines for management of autoimmune hepatitis. Gut 2011;60:16111629.

[9] Manns MP, Czaja AJ, Gorham JD, et al. Diagnosis and management of autoimmune hepatitis. Hepatology 2010;51:2193-2213.

[10] Alvarez F, Berg PA, Bianchi FB, et al. International Autoimmune Hepatitis Group Report: review of criteria for diagnosis of autoimmune hepatitis. J Hepatol 1999;31:929-938.

[11] Hennes EM, Zeniya M, Czaja AJ, et al. Simplified criteria for the diagnosis of autoimmune hepatitis. Hepatology 2008;48:169-176.

[12] Miyake $Y$, Iwasaki $Y$, Kobashi $H$, et al. Clinical features of autoimmune hepatitis diagnosed based on simplified criteria of the International Autoimmune Hepatitis Group. Dig Liver Dis 2010;42:210-215. 


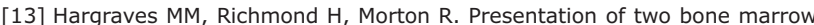
elements; the tart cell and the L.E. cell. Proc Staff Meet Mayo Clin 1948;23: 25-28.

[14] Mackay IR, Weiden S, Hasker J. Autoimmune hepatitis. Ann N Y Acad Sci $1965 ; 124: 767-780$

[15] Cowling DC, Mackay IR, Taft LI. Lupoid hepatitis. Lancet 1956;271:13231326.

[16] Parveen S, Morshed SA, Arima K, et al. Antibodies to Ro/La, Cenp-B, and snRNPs antigens in autoimmune hepatitis of North America versus Asia: patterns of immunofluorescence, ELISA reactivities, and HLA association. Dig Dis Sci 1998;43:1322-1331.

[17] Bottazzo GF, Florin-Christensen A, Fairfax A, Swana G, Doniach D, Groeschel-Stewart U. Classification of smooth muscle autoantibodies detected by immunofluorescence. J Clin Pathol 1976;29:403-410.

[18] Gabbiani G, Ryan GB, Lamelin JP, et al. Human smooth muscle autoantibody. Its identification as antiactin antibody and a study of its binding to "nonmuscular" cells. Am J Pathol 1973;72:473-488.

[19] Villalta D, Bizzaro N, Da Re M, Tozzoli R, Komorowski L, Tonutti E. Diagnostic accuracy of four different immunological methods for the detection of antiF-actin autoantibodies in type 1 autoimmune hepatitis and other liverrelated disorders. Autoimmunity 2008;41:105-110.

[20] Cotler SJ, Kanji K, Keshavarzian A, Jensen DM, Jakate S. Prevalence and significance of autoantibodies in patients with non-alcoholic steatohepatitis. J Clin Gastroenterol 2004;38:801-804.

[21] Bleibel W, Thukral C, Robson SC. Overlap between systemic lupus erythematosus and nonalcoholic steatohepatitis. J Clin Gastroenterol 2006;40:561-562.

[22] Tsuneyama K, Baba H, Kikuchi K, et al. Autoimmune features in metabolic liver disease: a single-center experience and review of the literature. Clin Rev Allergy Immunol 2013;45:143-148.

[23] Homberg JC. Autoimmunity induced by drugs. Immunological characteristics and etiopathogenic hypotheses. Presse Med 1984;13:2755-2760.

[24] Homberg JC, Andre C, Abuaf N. A new anti-liver-kidney microsome antibody (anti-LKM2) in tienilic acid-induced hepatitis. Clin Exp Immunol 1984;55:561-570.

[25] Rizzetto M, Doniach D. Types of 'reticulin' antibodies detected in human sera by immunofluorescence. J Clin Pathol 1973;26:841-851.

[26] Gueguen M, Meunier-Rotival M, Bernard O, Alvarez F. Anti-liver kidney microsome antibody recognizes a cytochrome P450 from the IID subfamily. J Exp Med 1988;168:801-806.

[27] Manns MP, Johnson EF, Griffin KJ, Tan EM, Sullivan KF. Major antigen of liver kidney microsomal autoantibodies in idiopathic autoimmune hepatitis is cytochrome P450db1. J Clin Invest 1989;83:1066-1072.

[28] Mix H, Weiler-Normann $C$, Thimme $R$, et al. Identification of CD4 T-cell epitopes in soluble liver antigen/liver pancreas autoantigen in autoimmune hepatitis. Gastroenterology 2008;135:2107-2118.

[29] Ma Y, Okamoto M, Thomas MG, et al. Antibodies to conformational epitopes of soluble liver antigen define a severe form of autoimmune liver disease. Hepatology 2002;35:658-664.

[30] Palioura S, Herkel J, Simonovic M, Lohse AW, Soll D. Human SepSecS or SLA/LP: selenocysteine formation and autoimmune hepatitis. Biol Chem 2010;391:771-776.

[31] Fallatah HI, Akbar HO. Autoimmune hepatitis as a unique form of an autoimmune liver disease: immunological aspects and clinical overview. Autoimmune diseases. 2012;2012:312817.

[32] Martini E, Abuaf N, Cavalli F, Durand V, Johanet C, Homberg JC. Antibody to liver cytosol (anti-LC1) in patients with autoimmune chronic active hepatitis type 2. Hepatology 1988;8:1662-1666.

[33] Czaja AJ, Manns MP. Advances in the diagnosis, pathogenesis, and management of autoimmune hepatitis. Gastroenterology 2010;139:5872 e54.

[34] Bogdanos DP, Mieli-Vergani G, Vergani D. Autoantibodies and their antigens in autoimmune hepatitis. Semin Liver Dis 2009;29:241-253.

[35] Terjung B, Bogsch F, Klein R, et al. Diagnostic accuracy of atypical p-ANCA in autoimmune hepatitis using ROC- and multivariate regression analysis. Eur J Med Res 2004;9:439-448.

[36] Terjung B, Spengler U, Sauerbruch T, Worman HJ. "Atypical p-ANCA" in IBD and hepatobiliary disorders react with a 50-kilodalton nuclear envelope protein of neutrophils and myeloid cell lines. Gastroenterology 2000;119: 310-322.

[37] Yokosawa S, Yoshizawa K, Ota M, et al. A genomewide DNA microsatellite association study of Japanese patients with autoimmune hepatitis type 1 . Hepatology 2007;45:384-390.

[38] Roozendaal C, de Jong MA, van den Berg AP, van Wijk RT, Limburg PC, Kallenberg CG. Clinical significance of anti-neutrophil cytoplasmic antibodies (ANCA) in autoimmune liver diseases. J Hepatol 2000;32:734-741.

[39] Longhi MS, Robson SC, Bernstein SH, Serra S, Deaglio S. Biological functions of ecto-enzymes in regulating extracellular adenosine levels in neoplastic and inflammatory disease states. J Mol Med 2013;91:165-172.
[40] Vergani D, Mieli-Vergani G. Aetiopathogenesis of autoimmune hepatitis World J Gastroenterol 2008;14:3306-3312.

[41] Czaja AJ, Carpenter HA, Santrach PJ, Moore SB. Genetic predispositions for the immunological features of chronic active hepatitis. Hepatology 1993; 18:816-822.

[42] Czaja AJ, Cookson S, Constantini PK, Clare M, Underhill JA, Donaldson PT. Cytokine polymorphisms associated with clinical features and treatment outcome in type 1 autoimmune hepatitis. Gastroenterology 1999;117: 645-652.

[43] Vogel A, Strassburg CP, Manns MP. Genetic association of vitamin D receptor polymorphisms with primary biliary cirrhosis and autoimmune hepatitis. Hepatology 2002;35:126-131.

[44] Manns MP, Griffin KJ, Sullivan KF, Johnson EF. LKM-1 autoantibodies recognize a short linear sequence in P450IID6, a cytochrome P-450 monooxygenase. J Clin Invest 1991;88:1370-1378.

[45] Shevach EM. Mechanisms of foxp3+ Tregulatory cell-mediated suppression. Immunity 2009;30:636-645.

[46] Shalev I, Schmelzle M, Robson SC, Levy G. Making sense of regulatory T cell suppressive function. Semin Immunol 2011;23:282-292.

[47] Longhi MS, Hussain MJ, Mitry RR, et al. Functional study of CD4+CD25+ regulatory T cells in health and autoimmune hepatitis. J Immunol 2006; 176:4484-4491.

[48] Longhi MS, Hussain MJ, Bogdanos DP, et al. Cytochrome P450IID6-specific CD8 $\mathrm{T}$ cell immune responses mirror disease activity in autoimmune hepatitis type 2. Hepatology 2007;46:472-484.

[49] Dwyer KM, Deaglio S, Gao W, Friedman D, Strom TB, Robson SC. CD39 and control of cellular immune responses. Purinergic Signal 2007;3:171-180.

[50] Vaughn BP, Robson SC, Burnstock G. Pathological roles of purinergic signaling in the liver. J Hepatol 2012;57:916-920.

[51] Longhi MS, Ma Y, Bogdanos DP, Cheeseman P, Mieli-Vergani G, Vergani D. Impairment of $\mathrm{CD} 4(+) \mathrm{CD} 25(+)$ regulatory T-cells in autoimmune liver disease. J Hepatol 2004;41:31-37.

[52] Eltzschig HK, Sitkovsky MV, Robson SC. Purinergic signaling during inflammation. N Engl J Med 2013;368:1260.

[53] Deaglio S, Robson SC. Ectonucleotidases as regulators of purinergic signaling in thrombosis, inflammation, and immunity. Adv Pharmacol 2011;61:301-332.

[54] Hasko G, Linden J, Cronstein B, Pacher P. Adenosine receptors: therapeutic aspects for inflammatory and immune diseases. Nat Rev Drug Discov 2008 7:759-770.

[55] Liberal R, Longhi MS, Mieli-Vergani G, Vergani D. Pathogenesis of autoimmune hepatitis. Best Pract Res Clin Gastroenterol 2011;25:653664.

[56] Grant CR, Liberal R, Holder BS, et al. Dysfunctional CD39 regulatory T cells and aberrant control of $\mathrm{T}$ helper type 17 cells in autoimmune hepatitis. Hepatology 2013.

[57] Zhao L, Tang Y, You Z, et al. Interleukin-17 contributes to the pathogenesis of autoimmune hepatitis through inducing hepatic interleukin- 6 expression. PloS One 2011;6:e18909.

[58] Fletcher JM, Lonergan R, Costelloe L, et al. CD39+Foxp3+ regulatory T Cells suppress pathogenic Th17 cells and are impaired in multiple sclerosis. J Immunol 2009;183:7602-7610.

[59] Regateiro FS, Howie D, Nolan KF, et al. Generation of anti-inflammatory adenosine by leukocytes is regulated by TGF-beta. Eur J Immunol 2011;41: 2955-2965.

[60] Friedman DJ, Kunzli BM, YI AR, et al. From the Cover: CD39 deletion exacerbates experimental murine colitis and human polymorphisms increase susceptibility to inflammatory bowel disease. Proc Natl Acad Sci U S A 2009;106:16788-16793.

[61] Longhi MS, Ma Y, Mitry RR, et al. Effect of CD4+ CD25+ regulatory T-cells on CD8 T-cell function in patients with autoimmune hepatitis. J Autoimmun 2005; 25:63-71.

[62] Longhi MS, Liberal R, Holder B, et al. Inhibition of interleukin-17 promotes differentiation of CD25(-) cells into stable Tregulatory cells in patients with autoimmune hepatitis. Gastroenterology 2012;142:1526-1535.

[63] Swain MG. Hepatic NKT cells: friend or foe? Clin Sci 2008;114:457-466.

[64] Dennert G, Aswad F. The role of NKT cells in animal models of autoimmune hepatitis. Crit Rev Immunol 2006;26:453-473.

[65] Beldi G, Wu Y, Banz Y, et al. Natural killer T cell dysfunction in CD39-null mice protects against concanavalin A-induced hepatitis. Hepatology 2008; 48:841-852.

[66] Deaglio S, Dwyer KM, Gao W, et al. Adenosine generation catalyzed by CD39 and CD73 expressed on regulatory $T$ cells mediates immune suppression. J Exp Med 2007;204:1257-1265.

[67] Summerskill WH, Korman MG, Ammon HV, Baggenstoss AH. Prednisone for chronic active liver disease: dose titration, standard dose, and combination with azathioprine compared. Gut 1975;16:876-883.

[68] Cook GC, Mulligan R, Sherlock S. Controlled prospective trial of corticosteroid therapy in active chronic hepatitis. Q J Med 1971;40:159-185. 
[69] Soloway RD, Summerskill WH, Baggenstoss AH, et al. Clinical, biochemical, and histological remission of severe chronic active liver disease: a controlled study of treatments and early prognosis. Gastroenterology $1972 ; 63: 820-833$

[70] Murray-Lyon IM, Stern RB, Williams R. Controlled trial of prednisone and azathioprine in active chronic hepatitis. Lancet 1973;1:735-737.

[71] Czaja AJ. Review article: the management of autoimmune hepatitis beyond consensus guidelines. Aliment Pharmacol Ther 2013;38:343-364.

[72] Stellon AJ, Hegarty JE, Portmann B, Williams R. Randomised controlled trial of azathioprine withdrawal in autoimmune chronic active hepatitis. Lancet $1985 ; 1: 668-670$.

[73] van Gerven NM, Verwer B], Witte BI, et al. Relapse is almost universal after withdrawal of immunosuppressive medication in patients with autoimmune hepatitis in remission. J Hepatol 2013;58:141-147.

[74] Lennard L. Implementation of TPMT testing. Br ] Clin Pharmacol 2013.

[75] Czaja AJ. Safety issues in the management of autoimmune hepatitis. Expert Opin Drug Saf 2008;7:319-333.

[76] Bajaj JS, Saeian K, Varma RR, et al. Increased rates of early adverse reaction to azathioprine in patients with Crohn's disease compared to autoimmune hepatitis: a tertiary referral center experience. Am J Gastroenterol 2005;100:1121-1125.

[77] Heneghan MA, Allan ML, Bornstein JD, Muir AJ, Tendler DA. Utility of thiopurine methyltransferase genotyping and phenotyping, and measurement of azathioprine metabolites in the management of patients with autoimmune hepatitis. J hepatol 2006;45:584-591.

[78] Montano-Loza AJ, Carpenter HA, Czaja AJ. Improving the end point of corticosteroid therapy in type 1 autoimmune hepatitis to reduce the frequency of relapse. Am J Gastroenterol 2007;102:1005-1012.

[79] Czaja AJ. Nonstandard drugs and feasible new interventions for autoimmune hepatitis: part I. Inflamm Allergy Drug Targets 2012;11:337-50.

[80] Danielsson A, Prytz H. Oral budesonide for treatment of autoimmune chronic active hepatitis. Aliment Pharmacol Ther 1994;8:585-590.

[81] Zandieh I, Krygier D, Wong V, et al. The use of budesonide in the treatment of autoimmune hepatitis in Canada. Can J Gastroenterol 2008;22:388392.

[82] Wiegand J, Schuler A, Kanzler S, et al. Budesonide in previously untreated autoimmune hepatitis. Liver Int 2005;25:927-934.

[83] Csepregi A, Rocken C, Treiber G, Malfertheiner P. Budesonide induces complete remission in autoimmune hepatitis. World J Gastroenterol 2006; 12:1362-1366.

[84] Manns MP, Woynarowski M, Kreisel W, et al. Budesonide induces remission more effectively than prednisone in a controlled trial of patients with autoimmune hepatitis. Gastroenterology 2010;139:1198-1206.

[85] Czaja AJ, Lindor KD. Failure of budesonide in a pilot study of treatmentdependent autoimmune hepatitis. Gastroenterology 2000;119:13121316.

[86] Richardson PD, James PD, Ryder SD. Mycophenolate mofetil for maintenance of remission in autoimmune hepatitis in patients resistant to or intolerant of azathioprine. J Hepatol 2000;33:371-375.

[87] Baven-Pronk AM, Coenraad MJ, van Buuren HR, et al. The role of mycophenolate mofetil in the management of autoimmune hepatitis and overlap syndromes. Aliment Pharmacol Ther 2011;34:335-343.

[88] Sharzehi K, Huang MA, Schreibman IR, Brown KA. Mycophenolate mofetil for the treatment of autoimmune hepatitis in patients refractory or intolerant to conventional therapy. Can J Gastroenterol 2010;24:588-592.

[89] Inductivo-Yu I, Adams A, Gish RG, et al. Mycophenolate mofetil in autoimmune hepatitis patients not responsive or intolerant to standard immunosuppressive therapy. Clin Gastroenterol Hepatol 2007;5:799-802.
[90] Devlin SM, Swain MG, Urbanski SJ, Burak KW. Mycophenolate mofetil for the treatment of autoimmune hepatitis in patients refractory to standard therapy. Can J Gastroenterol 2004;18:321-326.

[91] Hlivko JT, Shiffman ML, Stravitz RT, et al. A single center review of the use of mycophenolate mofetil in the treatment of autoimmune hepatitis. Clin Gastroenterol Hepatol 2008;6:1036-1040.

[92] Czaja AJ, Carpenter HA. Empiric therapy of autoimmune hepatitis with mycophenolate mofetil: comparison with conventional treatment for refractory disease. J Clin Gastroenterol 2005;39:819-825.

[93] Zachou K, Gatselis N, Papadamou G, Rigopoulou EI, Dalekos GN. Mycophenolate for the treatment of autoimmune hepatitis: prospective assessment of its efficacy and safety for induction and maintenance of remission in a large cohort of treatment-naive patients. J Hepatol 2011;55 636-646.

[94] Heneghan MA, Al-Chalabi T, McFarlane IG. Cost-effectiveness of pharmacotherapy for autoimmune hepatitis. Expert Opin Pharmacother 2006;7: 145-156.

[95] Matsuda S, Koyasu S. Mechanisms of action of cyclosporin. Immunopharmacology 2000;47:119-125.

[96] Jackson LD, Song E. Cyclosporin in the treatment of corticosteroid resistant autoimmune chronic active hepatitis. Gut 1995;36:459-461.

[97] Hyams JS, Ballow M, Leichtner AM. Cyclosporin treatment of autoimmune chronic active hepatitis. Gastroenterology 1987;93:890-893.

[98] Person JL, McHutchison JG, Fong TL, Redeker AG. A case of cyclosporinsensitive, steroid-resistant, autoimmune chronic active hepatitis. J Clin Gastroenterol 1993;17:317-320.

[99] Sherman KE, Narkewicz M, Pinto PC. Cyclosporin in the management of corticosteroid-resistant type I autoimmune chronic active hepatitis. J Hepatol 1994;21:1040-1047.

[100] Fernandes NF, Redeker AG, Vierling JM, Villamil FG, Fong TL. Cyclosporin therapy in patients with steroid resistant autoimmune hepatitis. Am J Gastroenterol 1999;94:241-248.

[101] Malekzadeh R, Nasseri-Moghaddam S, Kaviani MJ, Taheri H, Kamalian N, Sotoudeh M. Cyclosporin A is a promising alternative to corticosteroids in autoimmune hepatitis. Dig Dis Sci 2001;46:1321-1327.

[102] Aqel BA, Machicao V, Rosser B, Satyanarayana R, Harnois DM, Dickson RC. Efficacy of tacrolimus in the treatment of steroid refractory autoimmune hepatitis. J Clin Gastroenterol 2004;38:805-809.

[103] Van Thiel DH, Wright H, Carroll P, et al. Tacrolimus: a potential new treatment for autoimmune chronic active hepatitis: results of an open-label preliminary trial. Am J Gastroenterol 1995;90:771-776.

[104] Larsen FS, Vainer B, Eefsen M, Bjerring PN, Adel Hansen B. Low-dose tacrolimus ameliorates liver inflammation and fibrosis in steroid refractory autoimmune hepatitis. World J Gastroenterol 2007;13:3232-3236.

[105] Tannous MM, Cheng J, Muniyappa K, et al. Use of tacrolimus in the treatment of autoimmune hepatitis: a single centre experience. Aliment Pharmacol Ther 2011;34:405-407.

[106] Czaja AJ. Advances in the current treatment of autoimmune hepatitis. Dig Dis Sci 2012;57:1996-2010.

[107] Jothimani D, Cramp ME, Mitchell JD, Cross TJ. Treatment of autoimmune hepatitis: a review of current and evolving therapies. J Gastroenterol Hepatol 2011;26:619-627.

[108] Ilyas JA, O'Mahony CA, Vierling JM. Liver transplantation in autoimmune liver diseases. Best Pract Res Clin Gastroenterol 2011;25:765-782.

[109] Gautam M, Cheruvattath R, Balan V. Recurrence of autoimmune liver disease after liver transplantation: a systematic review. Liver Transpl 2006; 12:1813-1824. 